\title{
Comparison of SCIG and DFIG Wind Turbines during Variable Wind Speed
}

\author{
Amulya Viswambharan \\ Assistant Professor, Department of EEE, College of Engineering Munnar, Kerala, India.
}

\begin{abstract}
The Renewable energy sources, which have been expected to be a promising alternative energy source, can bring new challenges when it is connected to the power grid. However, the generated power from renewable energy source is always fluctuating due to environmental condition. In the same way Wind power injection into an electric grid affects the power quality due to the fluctuation nature of the wind and the comparatively new types of its generators. Fixed speed wind turbine equipped with Squirrel cage induction generator has the advantages of being simple, robust and reliable. However, it also contains some disadvantages of uncontrollable reactive power output, mechanical stress and limited power quality control. Owing to its fixed speed operation, fluctuations in wind speed are further transmitted as fluctuations in the mechanical torque and then in the electrical power output. In order to overcome the above mentioned problems associated with fixed-speed wind turbine system and to maximize the wind energy capture, variable speed wind turbines based on Doubly fed induction generator are becoming employed.
\end{abstract}

Keywords: Doubly fed induction generator (DFIG), Flicker, Power quality, Squirrel cage induction generator (SCIG), wind turbine

\section{INTRODUCTION}

Wind energy is one of the most cost-effective energy sources to produce electricity among various renewable energy sources. However, the generated power from renewable energy source is always fluctuating due to environmental condition. In the same way Wind power injection into an electric grid affects the power quality due to the fluctuation nature of the wind and the comparatively new types of its generators [2]. As the wind power penetration into the grid is increasing quickly, the influence of wind turbines on the power quality is becoming an important issue. One of the important power quality aspects is flicker. Flicker causes irritation to the consumer at the receiving end and results in a serious limitation for weak networks where the flicker effect can emerge. IEC 61400- 21 describes procedures for determining the power quality characteristics of wind turbines.

There are numerous of factors that affect flicker emission of grid-connected wind turbines during continuous operation, such as wind characteristics (e.g. mean wind speed, turbulence intensity) and grid conditions (e.g. short circuit capacity, grid impedance angle, load type) [7]. The type of wind turbine also has influence on flicker emission. Fixed-speed wind turbine system use a multistage gearbox and a standard squirrel-cage induction generator (SCIG), directly connected to the grid. The speed is not controllable and variable only over a very narrow range, in which only speeds higher than the synchronous speed are possible for generator operation. The fixed speed concept means that wind speed fluctuations are directly translated into electromechanical torque variations, this causes high mechanical and fatigue stresses on the system (turbine blades, gearbox and generator), and may result in swing oscillations between turbine and generator shaft [8]. Also the periodical torque dips due to the tower shadow and shear effect are not damped by speed variations, and result in higher flicker.
The variable-speed constant frequency system widely uses doubly fed induction generators (DFIGs) because of their many advantages. The rotor speeds of DFIGs can be controlled by the generators side, the active power and reactive power can be regulated independently by the rotor-side converter, and the voltage flicker is reduced [7]. In addition, their converters are only rated at about $25 \%$ $35 \%$ of the generator rating, and the rotor speeds can vary from $0.75 \mathrm{pu}$ to $1.25 \mathrm{pu}$. So the DFIGs will be widely used in wind farms because of their good performance.

In this paper an investigation of the flicker emission is presented, considering different types of WT (fixed and variable speed), operating under a variable of wind conditions. First the network and WT modeling approach is outlined and subsequently the results of the investigation are presented and discussed, illustrating the effect of the wind on the flicker levels resulting from the operation of fixed speed and variable speed wind turbine.

\section{WIND TURBINE MODELING}

Wind turbines are designed to capture the kinetic energy present in wind and convert it to electrical energy [1]. The vast majority of wind turbines that are currently installed use one of the three main types of electromechanical conversion system. The first type uses a squirrel cage induction generator to convert the mechanical energy to electrical energy. Owing to different operating speeds of the wind turbine rotor and the generator, a gearbox is necessary to match these speeds. The second type uses a doubly fed induction generator instead of squirrel cage induction generator. The stator winding of the generator is coupled to the grid, and the rotor winding to a power electronics converter.

\section{A.Modeling the Prime Mover of a WTGS}

Wind turbine power production depends on the interaction between the wind and the turbine rotor. The blades of a 
wind turbine rotor extract some of the energy flow from the angular velocity of the synchronously rotating air in motion, convert it into rotational energy, and then reference frame. $\omega_{\mathrm{r}}$ is rotor angular velocity; $r_{\mathrm{s}}$ and $r_{\mathrm{r}}$ are deliver it via a mechanical drive unit to the generator [8]. the stator and rotor resistances respectively. The flux

Wind energy is extracted through wind turbine blades and then transferred through a gearbox and the rotor hub to the mechanical energy in shaft [6]. The shaft drives the generator to convert the mechanical energy to electrical. The turbine model is based on the output power characteristics, expressed as:

$$
\begin{aligned}
& P_{m}=\frac{1}{2} \rho A v_{w}^{3} C_{p}(\lambda, \beta) \\
& \lambda=\frac{R_{\text {blade }} \omega_{r}}{v_{w}}
\end{aligned}
$$

Where $P_{\mathrm{m}}$ is the mechanical output power in watt, which depends on performance coefficient $C \mathrm{p}$, air density $\rho$, turbine swept area $A$ and wind speed $\mathrm{v}_{\mathrm{w}} \cdot \frac{1}{2} \rho A v_{w}^{3}$ is equal to the kinetic energy contained in the wind at particular speed $\mathbf{v}_{\mathrm{w}}$. The performance coefficient $C \mathrm{p}(\lambda, \beta)$, which depends on tip speed ratio $\lambda$ and blade pitch angle $\beta$, determines how much of the wind kinetic energy can be captured by the wind turbine system.

\section{B. Modeling the Electric Generator of a WTGS}

\section{Induction Generator Model}

The induction machine has typically been favoured for use in wind turbines due to the fact that induction generators do not need to be synchronized with the grid. Since wind turbines operate under varying wind speed conditions, resulting in varying shaft speeds [1]. Decoupling effect cannot be achieved in fixed-speed and rotor-resistance control based technologies. In a DFIG turbine, the decoupling of real and reactive power is achieved through the use of power electronics and flux-vector control [4]. In this subsection the considerations for modeling an induction machine and the concept of flux-vector control are introduced.

The electrical part of the machine is represented by a fourth-order state-space model and the mechanical part by a second-order system. All electrical variables and parameters are referred to the stator. All stator and rotor quantities are in the arbitrary two-axis reference frame (dq frame) as given in (3) - (6)

$$
\begin{aligned}
& \mathrm{V}_{\mathrm{qs}}=\mathrm{r}_{\mathrm{s}} \mathrm{I}_{\mathrm{qs}}+\omega_{\mathrm{e}} \lambda_{\mathrm{ds}}+\frac{d}{d t} \lambda_{\mathrm{qs}} \\
& \mathrm{V}_{\mathrm{ds}=} \mathrm{r}_{\mathrm{s}} \mathrm{I}_{\mathrm{ds}}-\omega_{\mathrm{e}} \lambda_{\mathrm{qs}}+\frac{d}{d t} \lambda_{\mathrm{ds}} \\
& \mathrm{V}_{\mathrm{qr}}=\mathrm{r}_{\mathrm{r}} \mathrm{I}_{\mathrm{qr}}+\left(\omega_{\mathrm{e}}-\omega_{\mathrm{r})} \lambda_{\mathrm{dr}}+\frac{d}{d t} \lambda_{\mathrm{qr}}\right. \\
& \mathrm{V}_{\mathrm{dr}}=\mathrm{r}_{\mathrm{r}} \mathrm{I}_{\mathrm{dr}}+\left(\omega_{\mathrm{e}}-\omega_{\mathrm{r})} \lambda_{\mathrm{qr}}+\frac{d}{d t} \lambda_{\mathrm{dr}}\right.
\end{aligned}
$$

Where $\mathrm{V}_{\mathrm{qs}}, \mathrm{V}_{\mathrm{ds}}, \mathrm{V}_{\mathrm{qr}}, \mathrm{V}_{\mathrm{dr}}$ are the $\mathrm{q}$ and $\mathrm{d}$-axis stator and rotor voltages, respectively. $I_{q s}, I_{d s}, I_{q r}, I_{d r}$ are the $q$ and $d$-axis stator and rotor currents, respectively. $\lambda_{\mathrm{qs}}, \lambda_{\mathrm{ds}}, \lambda_{\mathrm{qr}}, \lambda_{\mathrm{dr}}$ are the $\mathrm{q}$ and $\mathrm{d}$-axis stator and rotor fluxes, respectively. $\omega_{\mathrm{e}}$ is

linkage equations are given as;

$$
\begin{aligned}
& \lambda_{\mathrm{qs}}=\mathrm{L}_{\mathrm{s}} \mathrm{I}_{\mathrm{qs}}+\mathrm{L}_{\mathrm{m}} \mathrm{I}_{\mathrm{qr}} \\
& \lambda_{\mathrm{ds}}=\mathrm{L}_{\mathrm{s}} \mathrm{I}_{\mathrm{ds}}+\mathrm{L}_{\mathrm{m}} \mathrm{I}_{\mathrm{dr}} \\
& \lambda_{\mathrm{qr}}=\mathrm{L}_{\mathrm{m}} \mathrm{I}_{\mathrm{qs}}+\mathrm{L}_{\mathrm{r}} \mathrm{I}_{\mathrm{qr}} \\
& \lambda_{\mathrm{dr}}=\mathrm{L}_{\mathrm{m}} \mathrm{I}_{\mathrm{ds}}+\mathrm{L}_{\mathrm{r}} \mathrm{I}_{\mathrm{dr}}
\end{aligned}
$$

Where $\mathrm{L}_{\mathrm{s}}, \mathrm{L}_{\mathrm{r}}$ and $\mathrm{L}_{\mathrm{m}}$ are the stator, rotor, and mutual inductances, respectively, with $\mathrm{Ls}=\mathrm{L}_{\mathrm{ls}}+\mathrm{L}_{\mathrm{m}}$ and $\mathrm{L}_{\mathrm{r}}=\mathrm{L}_{\mathrm{lr}}+$ $\mathrm{L}_{\mathrm{m}}$; $\mathrm{L}_{\mathrm{ls}}$ being the self inductance of stator and $\mathrm{L}_{\mathrm{lr}}$ being the self inductance of rotor.

Solving (7) - (10) in terms of current equations:

$$
\begin{aligned}
& \mathrm{I}_{\mathrm{qs}}=\frac{1}{\sigma L s} \lambda_{\mathrm{qs}}-\frac{L m}{\sigma L s L r} \lambda_{\mathrm{qr}} \\
& \mathrm{I}_{\mathrm{ds}}=\frac{1}{\sigma L s} \lambda_{\mathrm{ds}}-\frac{L m}{\sigma L s L r} \lambda_{\mathrm{dr}} \\
& \mathrm{I}_{\mathrm{qr}}=\frac{1}{\sigma L r} \lambda_{\mathrm{qr}}-\frac{L m}{\sigma L s L r} \lambda_{\mathrm{qs}} \\
& \mathrm{I}_{\mathrm{dr}}=\frac{1}{\sigma L r} \lambda_{\mathrm{dr}}-\frac{L m}{\sigma L s L r} \lambda_{\mathrm{ds}}
\end{aligned}
$$

Where leakage coefficient $\sigma=\frac{L s L r-L m^{2}}{L s L r}$

When the induction motor operates as a generator, current direction will be opposite. Assuming negligible power losses in stator and rotor resistances, the active and reactive power outputs from stator and rotor side are given as:

$$
\begin{aligned}
& \mathrm{P}_{\mathrm{s}}=-\frac{3}{2}\left[\mathrm{~V}_{\mathrm{qs}} \mathrm{I}_{\mathrm{qs}}+\mathrm{V}_{\mathrm{ds}} \mathrm{I}_{\mathrm{ds}}\right] \\
& \mathrm{Q}_{\mathrm{s}}=-\frac{3}{2}\left[\mathrm{~V}_{\mathrm{qs}} \mathrm{I}_{\mathrm{ds}}-\mathrm{V}_{\mathrm{ds}} \mathrm{I}_{\mathrm{qs}}\right] \\
& \mathrm{P}_{\mathrm{r}}=-\frac{3}{2}\left[\mathrm{~V}_{\mathrm{qr}} \mathrm{I}_{\mathrm{qr}}+\mathrm{V}_{\mathrm{dr}} \mathrm{I}_{\mathrm{dr}}\right] \\
& \mathrm{Q}_{\mathrm{r}}=-\frac{3}{2}\left[\mathrm{~V}_{\mathrm{qr}} \mathrm{I}_{\mathrm{dr}}-\mathrm{V}_{\mathrm{dr}} \mathrm{I}_{\mathrm{qr}}\right]
\end{aligned}
$$

For fixed speed wind turbines only the stator winding is connected to the grid, generator and grid can exchange active and reactive power only through the stator terminals. Therefore the rotor does not need to be taken into account [13].

\section{SCIG WIND POWER SYSTEM}

The SCIG in this WTG concept can only operate within a narrow range of the rotational speed slightly above the synchronous speed. Because of these very small rotational speed variations, this type of WTG is considered to operate at fixed speed. As shown in Fig. 1, each individual WTG consists of a SCIG driven by a wind turbine through a mechanical shaft system and operates at a certain incoming wind velocity. The SCIG consumes reactive power and therefore is normally equipped with 
compensating capacitors for reactive compensation and improving the power factor [1].

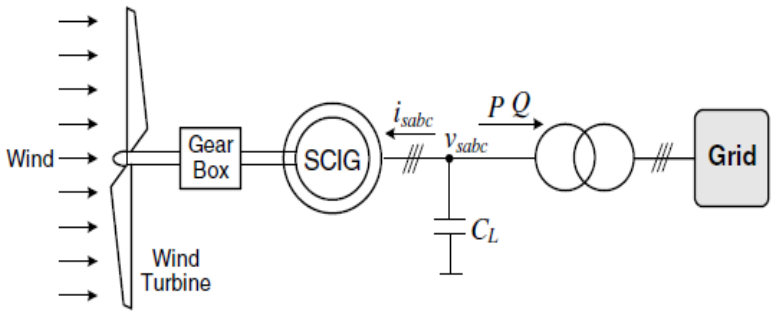

Fig.1. Configuration of the fixed-speed wind turbine generator

Since SCIG is of fixed speed generator, for a particular wind speed, the output active power is fixed as well. Thus, with the increase of wind speed, so does the output power until the nominal power is reached. The wind speed at this moment is called nominal wind speed. Beyond this speed, the pitch angle system will prevent the output power from exceeding the nominal value. That is, when the wind speed is below nominal value, the power capture can vary with the change of wind speed; when the wind speed is above nominal value, the pitch angle control system will limit the generated power by changing the pitch angle [3]. The wind turbine aerodynamic model and the wind power model are represented by a user-defined component in PSCAD/EMTDC. The PSCAD/EMTDC software library provides the standard model of the SCIG.

\section{DFIG WIND POWER SYSTEM}

A double-Fed induction generator is as a standard wound rotor induction generator with its stator windings directly connected to the power grid and rotor connected to the power grid through a frequency converter [4]. In modern DFIG designs, the frequency converters are usually built by two, three phase self commutated back-to-back PWM converters with an intermediate capacitor link for DC bus voltage regularity. The converter that is connected to the rotor called 'rotor side converter' and the other named 'grid side converter'. Vector control is one of the most common methods applied to DFIG to control the flow of active and reactive power between the stator and the grid. It can be applied on both rotor side converter (RSC) and grid side converter (GSC). The objective of the RSC is to govern both the stator-side active and reactive powers independently, while the objective of the GSC is to keep the dc-link voltage constant regardless of the magnitude and direction of the rotor power [7]. The GSC control scheme can also be designed to regulate the reactive power. By controlling the grid and rotor converters, the DFIG can be adjusted to achieve many capabilities versus conventional squirrel cage induction generators.

PSCAD/EMTDC software package offers suitable models for evaluating DFIG wind turbine. Moreover, it includes a generic wind turbine governor and different wind resource patterns.

The unit transformer and grid are both modeled using inbuilt blocks supplied by PSCAD/EMTDC. The unit transformer is a wye-delta 2-MVA transformer with a primary voltage of $34.5 \mathrm{kV}$ and a secondary voltage of $0.69 \mathrm{kV}$. During the development and testing phase, the grid is represented by a $34.5-\mathrm{kV}$ voltage source. The Complete model implemented in PSCAD/EMTDC is shown in Fig.2.

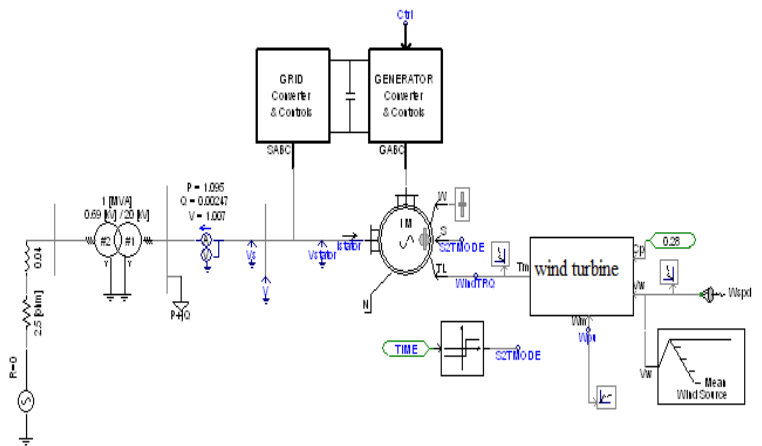

Fig.2- Schematic of DFIG for WECS in PSCAD/EMTDC

\section{SIMULATION RESULTS}

In this paper simulations were carried out for two cases of operating wind turbine:

Case 1: a wind turbine with SCIG

Case 2: a wind turbine with DFIG

In the real wind farm, the wind velocity is always fluctuating. To compare the dynamic response of each model, all the wind turbines experience identical wind with the mean velocity of $11 \mathrm{~m} / \mathrm{s}$, as shown in Fig. 3(a). Figure 3(b)-(d) compares the active power, reactive power, and voltage magnitude at the PCC by using the SCIG WTG equivalent model and the DFIG WTG model, respectively.

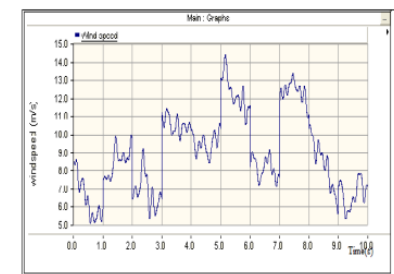

(a1)

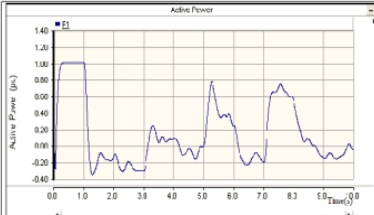

(b1)

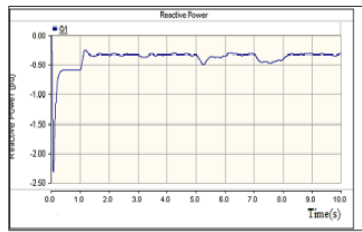

(c1)

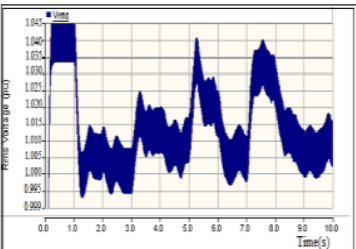

(d1)

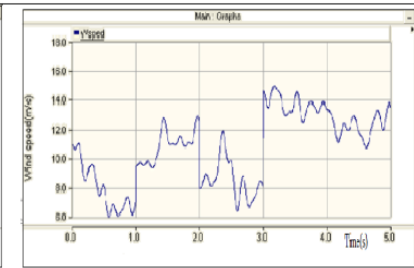

(a2)

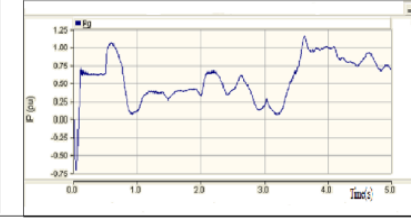

(b2)

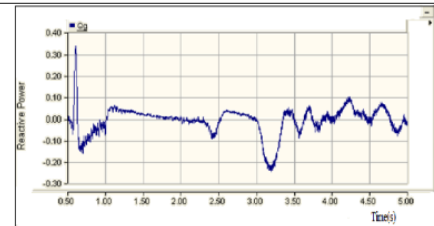

(c2)

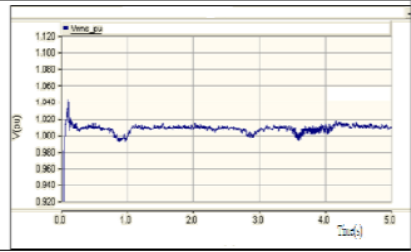

(d2)
Fig.3. Wind speed, Active power, reactive power and voltage profile for SCIG and DFIG wind turbine model 
It has been observed that with random variation of wind speed, both the active power and reactive power fluctuate continuously as illustrated in Fig 3(b) and Fig. 3(c).The changes in generator voltage is shown in Fig 3(d). According to Fig.3 (d1) wind turbine with SCIG shows a voltage fluctuation of $4.5 \%$. In the wind turbine with DFIG, active power output varies between $0.2 \mathrm{pu}$ to 1.0 $\mathrm{pu}$, and ultimately causes voltage variations between 0.99 pu and $1.01 \mathrm{pu}$. This represents a $2 \%$ variation compared to the nominal system voltage. It is clear that the voltage fluctuation is very small compared to SCIG wind turbine.

Simulation results shown that, by the replacement of a fixed speed wind turbines with DFIG wind turbine can reduce the flicker emission. In this way, the DFIG wind turbine with its grid-side convertor behaves similarly to a STATCOM at the wind Turbine terminal. The difference is that the grid side converter is already there without any additional cost in the case of a doubly fed induction generator. With grid-side convertor of DFIG wind turbine alternative flicker mitigation is carried out to control measure directly controlling the voltage at the PCC, which can also be realized by regulating the reactive power of the PWM voltage source converters. The aim of the voltage controller is to keep the voltage at a constant value such that the voltage fluctuations as well as flicker are reduced.

\section{CONCLUSION}

A significant feature of wind power in contrast to conventional power is fluctuation of output power due to wind speeds and turbine locations. This fluctuation affects the voltage profile and system stability. The detailed model of the grid-connected wind turbine containing DFIGs and SCIGs is established in this paper. These models are compared by simulation studies in the PSCAD/EMTDC environment under different wind velocity and fluctuation conditions. For a fixed-speed wind turbine, there is no active control over the power output of the machine, once the rotor blade pitch angle is set. The DFIG technology allows extracting maximum energy from the wind for low wind speeds by optimizing the turbine speed, while minimizing mechanical stresses on the turbine during variable wind speed. Flicker mitigation can be realized by using the DFIG wind turbine in fixed speed wind farm which is significant in the flicker emission.

\section{REFERENCES}

1] T. Abedinzadeh, M. Ehsan, and D. Talebi, "Dynamic Modeling and Control of Induction Generators in Wind Turbines", International Journal of Computer and Electrical Engineering, Vol.4, No.2, April 2012.

[2] Z. Chen and E. Spooner, "Grid power quality with variable speed wind turbines," Energy Conversion, IEEE Transactions on, vol. 16, pp. 148-154, 2001.

[3] H. Li* Z. Chen, "Overview of different wind generator systems and their comparisons", IET Renew. Power Gener, 2008, Vol. 2, No. 2 , pp. $123-138$

[4] Taher Abedinzadeh, Hadi Afsharirad, Mohammad Nazaraliloo, Saeid Masoumi, "Modelling and performance analysis of DoublyFed Induction Wind Turbines Using PSCAD/EMTDC”, Canadian Journal on Electrical and Electronics Engineering Vol. 3, No. 1, January 2012

5] M.G.Sugirtha, Dr. P.Latha, "Analysis of Power Quality Problems in Grid Connected Wind Power Plant, International Conference on
Recent Advancements in Electrical”, Electronics and Control Engineering, 2011

[6] Yu Zou, Malik E. Elbuluk, and Yilmaz Sozer, "Simulation Comparisons and Implementation of Induction Generator Wind Power Systems", IEEE Transactions on Industry Applications, Vol. 49, No. 3, May/June 2013

[7] T. Sun, Z. Chen and F. Blaabjerg, "Flicker study on Variable speed Wind Turbines with Doubly Fed Induction Generators," IEEE Trans.on energy conversion, vol. 20, no. 4, pp. 896-904, December 2005

[8] L.L. Ntwasa, A. K. Saha, and N.M. Ijumba, "Simulation Study of Induction Generator-based Wind Turbine", International Conference on Power System Technology,2010

[9] Meegahapola, L., Littler, T. ; Fox, B. \&Kennedy, J., "Voltage and Power Quality Improvement Strategy for a DFIG Wind Farm during Variable Wind Conditions", Power and Energy Society General Meeting, IEEE pp.1-5, Sep.2010.

[10] Manitoba HVDC Research Centre, "PSCAD/EMTDC User's Manual Guide", Version 4.2, 2010.

[11] $\AA$. Larsson, "Flicker emission of wind turbines during continuous operation," IEEE Trans. Energy Conversion., vol. 17, no. 1, pp. 114-118, Mar. 2002.

[12] Wind Turbine Generator Systems Part 21: Measurement and Assessment of Power Quality Characteristics of Grid Connected Wind Turbines, IEC Standard 614000-21, 2001.

[13] Ackermann T. Wind power in power systems. John Willey and Sons; 2005.

[14] Mithunprakash G Vyas, BSEE, "Simulation and Modeling of Wind Power Plants": A Pedagogical Approach, The University of Texas at Austin, May 2010.

[15]Tao Sun, "Power Quality of Grid-Connected Wind Turbines with DFIG and Their Interaction with the Grid", Institute of Energy Technology Aalborg University, Denmark May 2004

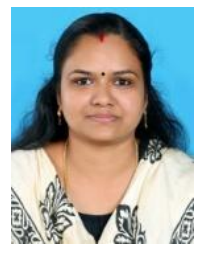

\section{BIOGRAPHY}

Amulya Viswambharan received the B.Tech. degree in Electrical and Electronics Engineering from College of Engineering Perumon, CUSAT, Kerala, in the year of 2006. M.Tech. degree in Power Systems from National Institute of Technology, Calicut, in 2014. Currently working as Assistant Professor in the Department of Electrical and Electronics Engineering at College of Engineering Munnar, Kerala. 